\title{
Acoustic Emission Characteristics and Failure Mechanism of Fractured Rock under Different Loading Rates
}

\author{
Yongzheng Zhang, 1,2 Gang Wang, ${ }^{1,2}$ Yujing Jiang, ${ }^{2}$ Shugang Wang, \\ Honghua Zhao, ${ }^{4}$ and Wenjun Jing ${ }^{5}$ \\ ${ }^{1}$ Shandong Provincial Key Laboratory of Civil Engineering Disaster Prevention and Mitigation, \\ Shandong University of Science and Technology, Qingdao 266590, China \\ ${ }^{2}$ State Key Laboratory of Mining Disaster Prevention and Control Co-Founded by Shandong Province and the Ministry of \\ Science and Technology, Shandong University of Science and Technology, Qingdao 266590, China \\ ${ }^{3}$ Research Center of Geotechnical and Structural Engineering, Shandong University, Jinan 250061, China \\ ${ }^{4}$ State Key Laboratory of Structural Analysis for Industrial Equipment, Dalian University of Technology, Dalian 116024, China \\ ${ }^{5}$ College of Pipeline and Civil Engineering, China University of Petroleum, Qingdao 266555, China \\ Correspondence should be addressed to Gang Wang; wanggang1110@gmail.com
}

Received 13 June 2017; Revised 21 August 2017; Accepted 12 September 2017; Published 15 October 2017

Academic Editor: M. I. Herreros

Copyright (c) 2017 Yongzheng Zhang et al. This is an open access article distributed under the Creative Commons Attribution License, which permits unrestricted use, distribution, and reproduction in any medium, provided the original work is properly cited.

To study the loading rate dependence of acoustic emissions and the failure mechanism of fractured rock, biaxial compression tests performed on granite were numerically simulated using the bonded particle model in Particle Flow Code (PFC). Uniaxial tests on a sample containing a single open fracture were simulated under different loading rates ranging from 0.005 to $0.5 \mathrm{~m} / \mathrm{s}$. Our results demonstrate the following. (1) The overall trends of stress and strain changes are not affected by the loading rate; the loading rate only affects the strain required to reach each stage. (2) The strain energy rate and acoustic emission (AE) events are affected by the loading rate in fractured rock. With an increase in the loading rate, AE events and the strain energy rate initially increase and then decrease, forming a fluctuating trend. (3) Under an external load, the particles within a specimen are constantly squeezed, rotated, and displaced. This process is accompanied by energy dissipation via the production of internal tensile and shear cracks; their propagation and coalescence result in the formation of a macroscopic rupture zone.

\section{Introduction}

Fractured rock is commonly encountered in engineering projects in various fields, including transportation, national defense, water conservation, hydropower engineering, and mine exploitation. In recent years, the failure of engineering projects because of the weakness of rock joints has been frequently observed. Various geological disasters, landslides, and debris flow have created serious threats to human life and property and significant economic losses. These geological hazards are often macroscopic manifestations of rock mass instability. The instability of jointed rock mass has attracted the attention of experts and scholars worldwide. The existence of joints and fractures often leads to a reduction in rock strength and an increase in deformation, resulting in distinct inhomogeneity and anisotropy in the rock mass. In addition, the existence of cracks increases the likelihood of block cracking and sliding, which is likely to further cause rock instability. From the 1960s through the 1990s, significant advances in understanding the role of rock joints and rupture mechanisms of fracturing rock were achieved [1-6]. In the twentyfirst century, many new technologies have been developed and used in scientific research, such as computed tomography (CT) scanning and acoustic emission. Simultaneously, numerical simulation techniques (e.g., rock failure process analysis (RFPA) and Particle Flow Code (PFC)) have been vastly improved and have enabled significant progress in modeling rock failure processes.

Vásárhelyi and Bobet [7] conducted uniaxial compression tests on prefabricated double-slit rectangular specimens 
and used the displacement discontinuity method to simulate the failure process. The authors were able to determine the crack initiation stress, the propagation direction of new cracks, and crack coalescence characteristics. Wong et al. [8] performed an experimental study of the crack propagation process and the peak intensity of three parallel prefabricated friction cracks in analog materials. Sahouryeh et al. [9] conducted biaxial compression tests on specimens with a builtin circular crack composed of transparent resin material and found that the crack extended along the loading direction. Lee and Jeon [10] used two types of materials with different built-in single and multigroup geometric distributions of cracks in compression tests and studied the results of these tests. Wang et al. [11] studied the failure mode of internal macrocracks using RFPA $^{3 \mathrm{D}}$ and evaluated the uniaxial compressive strength and fracture evolution processes. Ren and Hui [12] studied microdamage and failure mechanisms using CT scanning during uniaxial compression tests on sandstone with a single crack. Li et al. [13] analyzed the crack propagation process associated with damage evolution using CT real-time scanning tests on a rock-like material with a built-in single penny-shaped crack. Yang et al. [14] monitored the acoustic emission characteristics of the loading process using uniaxial compression tests on sandstone with cracks and discussed the effect of pore size distribution on the strength and fracture process.

Previous studies have applied advanced techniques to explore the crack propagation and evolution process in fractured rock specimens and have revealed the failure mechanisms of fractured rocks to a certain extent. However, little is known about the effect of the loading rate on acoustic emission and failure mechanisms. Therefore, in this work, PFC is used to study the impact of the loading rate on the fracture mechanisms of prefabricated rock with cracks under uniaxial compression tests.

\section{Basic Principles of Fracture Evolution in Rock Mass}

Griffith [15] found that the actual tensile strength of materials was usually significantly smaller than the theoretical value and that brittle materials typically contain a large number of randomly distributed small defects and cracks. These defects and cracks change the stress propagation direction, causing energy to accumulate around the crack, thereby leading to stress concentration and a reduction in the fracture strength of the material. Based on the theory of energy balance, a relationship between the critical stress of crack initiation and crack size was established by Griffith. It is believed that crack propagation that generates a new crack surface will consume the energy expended by external forces. This process will lead to an increase in the amount of strain stored in the material and will promote further expansion of the crack until failure of the material. Under the action of pure tensile and/or compressive stress, the total energy $U$ of an infinite plate with a crack contains an energy component specified by the following equation [16]:

$$
U=U_{t}+U_{c}-W+U_{s},
$$

where $U$ is the total energy stored in the infinite plate, $U_{t}$ represents the initial total elastic strain energy, $U_{c}$ is the total elastic strain energy released by the crack on the upper and lower surfaces of the crack length of $2 a, W$ is the work performed by the external force, and $U_{s}$ is the free surface energy.

According to the theory of elastic mechanics, the energy components can be expressed as

$$
U=\frac{\sigma^{2} A}{2 E^{\prime}} \pm \frac{\pi \sigma^{2} a^{2}}{E^{\prime}}-\frac{\sigma \varepsilon A}{2}+4 a \gamma_{s},
$$

where $U$ is the total energy stored in the infinite plate; $\sigma$ is the external load; $a$ is the half length of the crack; $E^{\prime}$ is the effective Young's modulus, $E^{\prime}=E /\left(1-\nu^{2}\right) ; \nu$ is Poisson's ratio; $A$ is the area of the infinitely thin plate; $\varepsilon$ is the average axial strain; and $\gamma_{s}$ is the surface energy required to increase the surface area because of crack length expansion.

Griffith defined the critical equilibrium condition of the material damage as

$$
\frac{\partial U}{\partial a}=0
$$

Substituting (2) into (3) yields

$$
\sigma \sqrt{\pi a}=\sqrt{2 E^{\prime} \gamma_{S}}
$$

This formula indicates that the ideal conditions for brittle material breakage are mainly related to the external force, crack length, Young's modulus, Poisson's ratio, and surface energy. Equation (4) can be rewritten as

$$
\frac{\pi \sigma^{2} a}{E^{\prime}}=2 \gamma_{s}
$$

The left part of (5) is the rate of elastic strain energy release of the crack, which is the energy source for crack growth and is denoted by $G$, such that $G=\pi \sigma^{2} a / E^{\prime}=\left(1-\mu^{2}\right) \pi \sigma^{2} a / E$. Griffith's theory states that $G=G_{c}$ is the critical condition for crack initiation, where $G_{c}$ is the critical elastic strain energy release rate.

\section{Introduction of PFC and Determination of Microparameters}

3.1. Introduction of PFC. PFC $[17,18]$ is an implementation of a simulation technique developed by Cundall based on the discrete-element method. This technique uses disk-like particles or spherical particles to simulate and analyze the mechanics of materials and deformation problems; it has been widely used in the field of geotechnical engineering. Researchers have used this technique to simulate continuous and discontinuous macro/mesomechanical behavioral characteristics [19-21]. In the simulation, the interaction models of two contact particles include the contact stiffness model, the sliding model, and the bond model. In the calculation process, particle motion always obeys Newton's laws of motion and the force displacement law. The contact 


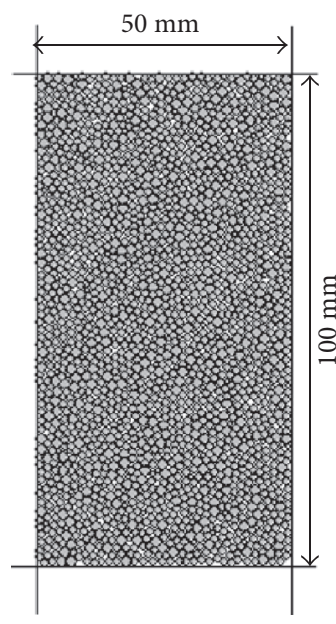

(a)

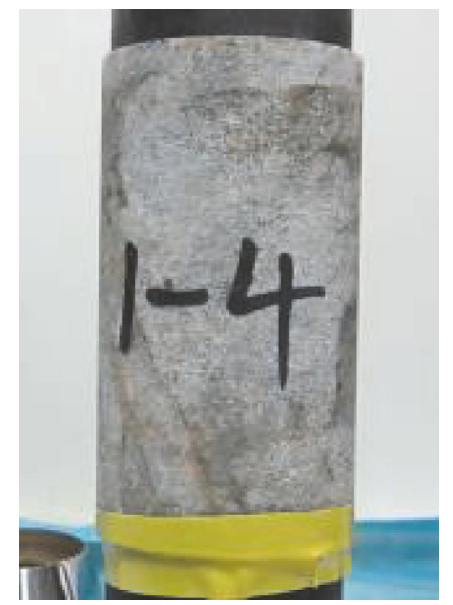

(b)
Figure 1: PFC model (a) and granite specimen (b).

stiffness model is largely based on the contact forces between the particles. The sliding model is based on the inherent characteristics of the contact sphere, namely, that it has no normal tensile strength and that the particles are allowed to slide across a range of shear strengths. The cohesive model is related to the mesodamage of particle aggregates; it is used to represent the strength properties of a specimen by setting the normal tensile strength and tangential shear strength. When the external stress acting on a bond exceeds the ultimate tensile strength and ultimate shear strength, the bond breaks. Microcracks are then generated at the bonding position. With the help of the FISH language in PFC, we can monitor the entire process of microscopic damage.

3.2. Determination of Microparameters. Biaxial compression tests on granite in the underground caverns of the Huangdao State Oil Reserves were virtually simulated using the bonded particle model in PFC. The numerical model is illustrated in Figure 1. The dimensions of the numerical model were $100 \mathrm{~mm} \times 50 \mathrm{~mm}$. The numerical model dimensions are consistent with the laboratory test dimensions. In the simulation model, the minimum particle radius was $0.3 \mathrm{~mm}$, and the particle size ratio was 1.66 [22].

Triaxial compression tests were conducted using a TAW2000 microcomputer-controlled electrohydraulic servo testing machine. PFC was run in a "trial-and-error" mode with repeated calibration of microscopic parameters until the macromechanical parameters of the particle flow model were sufficiently similar to the mechanical parameters of granite. The physical and mechanical properties of the microparameters are listed in Table 1.

In this study, loading rates within the quasi-dynamic (strain rate: $10^{-1} \sim 10^{1} \mathrm{~s}^{-1}$ ) and dynamic (strain rate: $10^{1} \sim 10^{4} \mathrm{~s}^{-1}$ ) loading ranges were selected [23], and the effect of loading rate on the mechanical properties of rock materials was studied. Therefore, uniaxial compression tests of fractured rock masses under 4 loading rates of $0.005 \mathrm{~m} / \mathrm{s}$, $0.01 \mathrm{~m} / \mathrm{s}, 0.05 \mathrm{~m} / \mathrm{s}$, and $0.5 \mathrm{~m} / \mathrm{s}$ were designed.
TABLE 1: Microparameters of the rock sample.

\begin{tabular}{lcc}
\hline Microparameters & Values & Remark \\
\hline Minimum radius $(\mathrm{mm})$ & 0.3 & \\
Particle radius ratio & 1.66 & \\
Particle density $\left(\mathrm{kg} \cdot \mathrm{m}^{-3}\right)$ & 2800 & $\begin{array}{c}\text { Uniform } \\
\text { distribution }\end{array}$ \\
Particle contact modulus $(\mathrm{GPa})$ & 5.0 & \\
Particle stiffness ratio & 3.0 & \\
Particle friction coefficients & 0.8 & \\
Parallel bond normal strength $(\mathrm{MPa})$ & $80 \pm 10$ & Normal \\
& & distribution \\
Parallel bond shear strength (MPa) & $160 \pm 10$ & Normal \\
Parallel bond modulus (GPa) & 43.0 & \\
Parallel bond stiffness ratio & 3.0 & \\
Parallel bond radius multiplier & 1.0 & \\
\hline
\end{tabular}

In dynamic problems, the damping parameters used in the model should have distinct physical meaning and should be reduced to values that are physically reasonable. Zhong et al. carried out a series of laboratory experiments on freefalling, colliding, and rebounding steel balls [24]. According to the experimental results, Zhou et al. carried out the corresponding $\mathrm{PFC}^{2 \mathrm{D}}$ simulation [25]. The results of the $\mathrm{PFC}^{2 \mathrm{D}}$ simulation are in good agreement with theoretical solutions when a tensile viscous damping model is applied.

In the $\mathrm{PFC}^{2 \mathrm{D}}$ numerical test of free-falling, colliding, and rebounding steel balls, as the viscous damping ratio $\zeta$ increases, the amount of energy absorbed through collision damping increases and the particle rebound height decreases. The numerical simulation results show that, in the $\mathrm{PFC}^{2 \mathrm{D}}$ model, the corresponding viscous damping ratio, $\zeta$, is 0.16 .

In real rocks, seismic energy generally experiences attenuation due to the inhomogeneity present in the interior of Earth [26]. Recently, Hazzard and Damjanac discussed the principle of describing the damping coefficient value in terms of energy and suggested that a larger value should be adopted to estimate energy changes in a dynamic test [27]. A damping coefficient of 0.1 should be used to ensure that the ratio of kinetic energy to strain energy change was very close to the seismic events, as described by McGarr [28]. Therefore, in this study, the damping coefficient value was set to 0.1 .

The physical and mechanical properties of the abovementioned calibration were used in the particle flow model. The granite compression test was simulated under confining stresses of 3, 6, and $10 \mathrm{MPa}$. In this paper, triaxial compression tests were performed by displacement control with a loading rate of $0.01 \mathrm{~mm} / \mathrm{s}$. Table 3 lists the peak strength of the granite and the bonded particle model at different confining stresses.

Figure 2 shows the stress-strain curves at different confining stresses. Table 3 lists the peak strength of granite and the bonded particle model at different confining stresses. Figure 2 and Table 2 demonstrate that, with an increase in the confining stress, the yield stress and the peak strength of the specimens increased, and the numerical model results were 


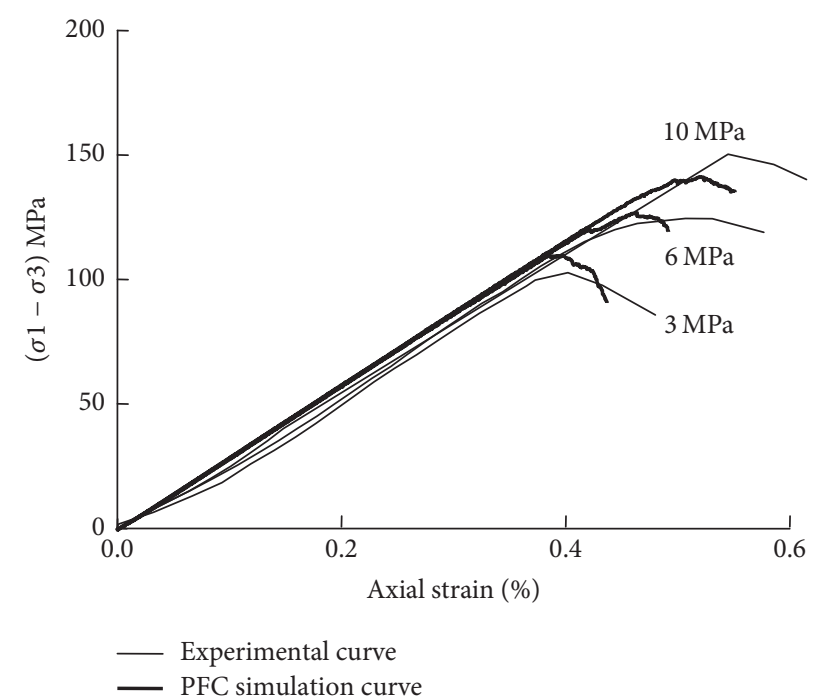

Figure 2: Stress-strain curves under different confining stresses.

TABle 2: Peak strength of granite and the bonded particle model under different confining stresses.

\begin{tabular}{lccc}
\hline Peak strength (MPa) & \multicolumn{3}{c}{ Confining stress (MPa) } \\
& 3 & 6 & 10 \\
\hline Experimental value & 110.4 & 130.5 & 162.6 \\
Simulation value & 112.6 & 132.8 & 151.2 \\
\hline
\end{tabular}

TABLE 3: Numerical results of the uniaxial compression test under different loading rate conditions.

\begin{tabular}{lcccc}
\hline Loading rate $(\mathrm{m} / \mathrm{s})$ & 0.005 & 0.01 & 0.05 & 0.5 \\
\hline Uniaxial compressive strength $(\mathrm{MPa})$ & 68.50 & 68.53 & 68.70 & 75.60 \\
Peak strain $(\%)$ & 0.318 & 0.320 & 0.323 & 0.330 \\
\hline
\end{tabular}

in good agreement with the experimental results. The final failure mode of the test specimen is shown in Figure 3 for the case of a $6 \mathrm{MPa}$ confining stress.

In this study, we examined the fracture behavior of rock specimens using the $\mathrm{PFC}^{2 \mathrm{D}}$ software, as shown in Figure 4. The model featured 8337 particles and 20974 contacts between the particles. A prefabricated crack with an angle of $45^{\circ}$ and a length of $0.025 \mathrm{~mm}$ was created in the specimen. The prefabricated crack was established using the FISH language to identify the fracture area particles, and the particles were then removed from the fracture area.

As shown in Figure 5, a biaxial compression numerical model was used to load the aggregate of particles with a simulated loading plate at the top and bottom of the wall. The confining pressure on the aggregate of the left and right two walls throughout the calculation process was constant. In Figure 5, $h$ and $w$ indicate the height and width of the specimen, respectively, and $V_{P}$ indicates the loading speed of the loaded wall.

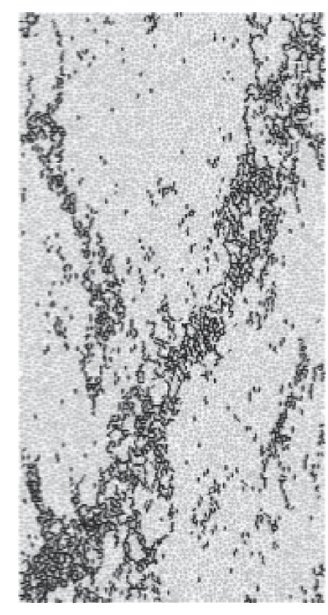

(a) Particle flow sample

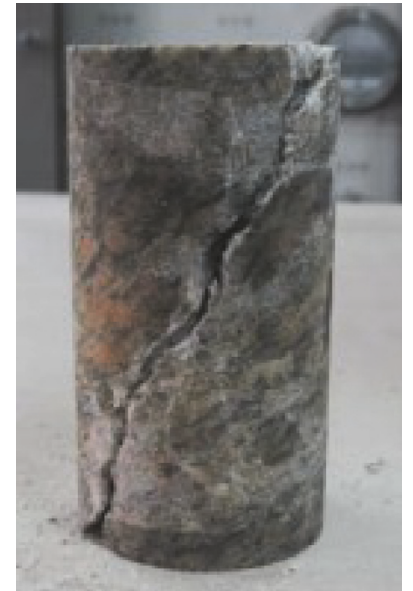

(b) Granite specimen
FIGURE 3: Failure mode of granite in compression at a confining stress of $6 \mathrm{MPa}$.

\section{Establishment of a Numerical Model for a Single Fractured Rock Mass and Loading Scheme}

In the initial establishment of a numerical compression model, the sample consisted of 4 pieces of rigid wall (see Figure 4(b)). The load acted on walls 1 and 3; walls 2 and 4 provided lateral restraint. When the uniaxial compression test was performed, the two side constraints were removed, but the bottom and top boundary walls were retained. Using the FISH language, the loading and unloading processes were determined for the upper and lower walls. To study the effect of loading rate on the mechanical properties of rock materials, uniaxial compression tests at loading rates of 0.005 , $0.01,0.05$, and $0.5 \mathrm{~m} / \mathrm{s}$ were designed.

\section{Results}

The uniaxial compression numerical tests were performed on fractured rock masses at loading rates of $0.005,0.01,0.05$, and $0.5 \mathrm{~m} / \mathrm{s}$. Quantitative analyses of the effects of the loading rate on the stress-strain, failure process, failure mode, strain rate, and acoustic emission under compression were performed. The mechanism of rock failure was analyzed in terms of crack development, particle rotation, and energy dissipation.

5.1. The Effect of Loading Rate on Deformation Characteristics. The effect of the loading rate on the stress-strain curves and the deformation characteristics of fractured rock mass was analyzed, and the numerical results are presented in Table 3. Figure 6 shows the stress-strain curves of fractured rock under uniaxial compression at different loading rates. Figure 7 shows the relationship between the uniaxial compressive strength and the peak strain of the fractured rock samples for different loading rates.

As shown in Figure 6, during the compression process, the fractured rock experienced initial compaction, hardening 


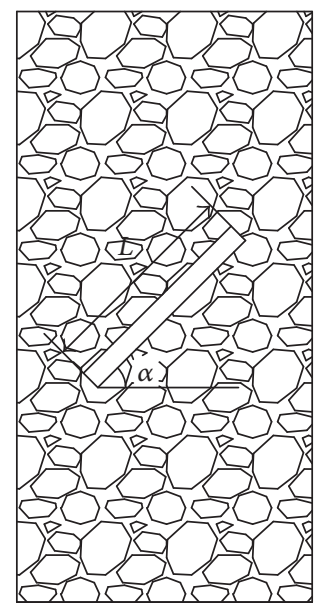

(a)

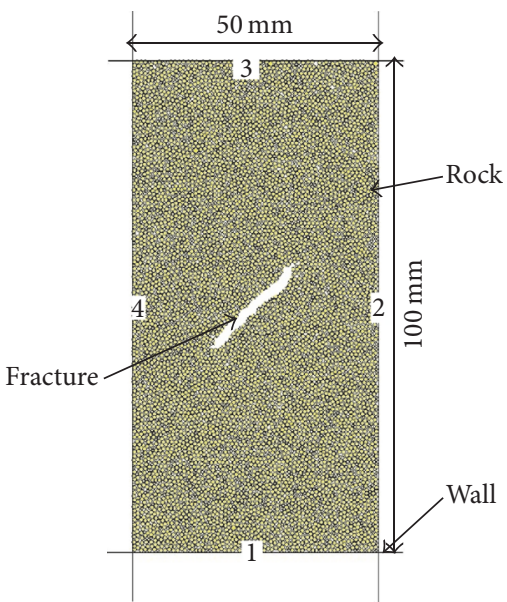

(b)

FIGURE 4: Fractured rock sample (a) and numerical model implemented in PFC (b).

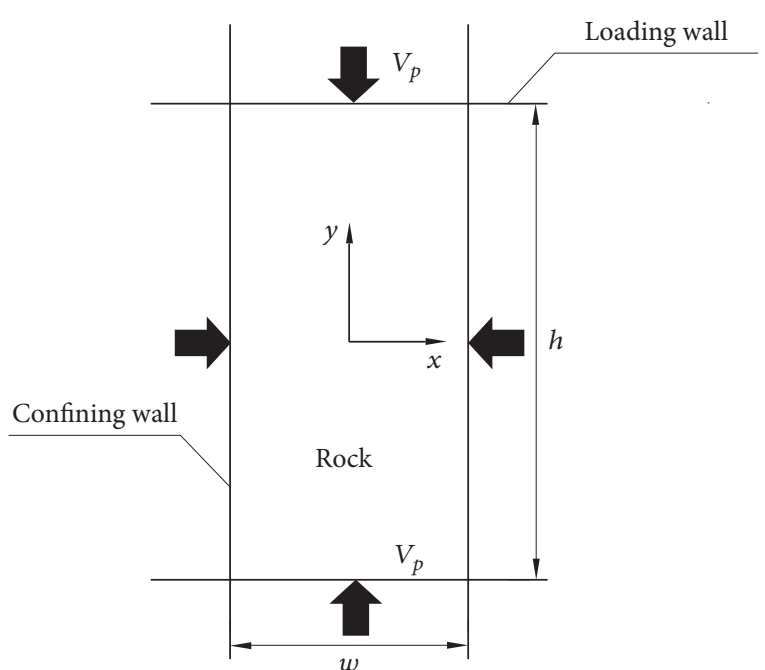

FiguRE 5: Schematic diagram of biaxial compression test.



FIGURE 6: Curve of stress versus strain for uniaxial compression tests performed at different loading rates.

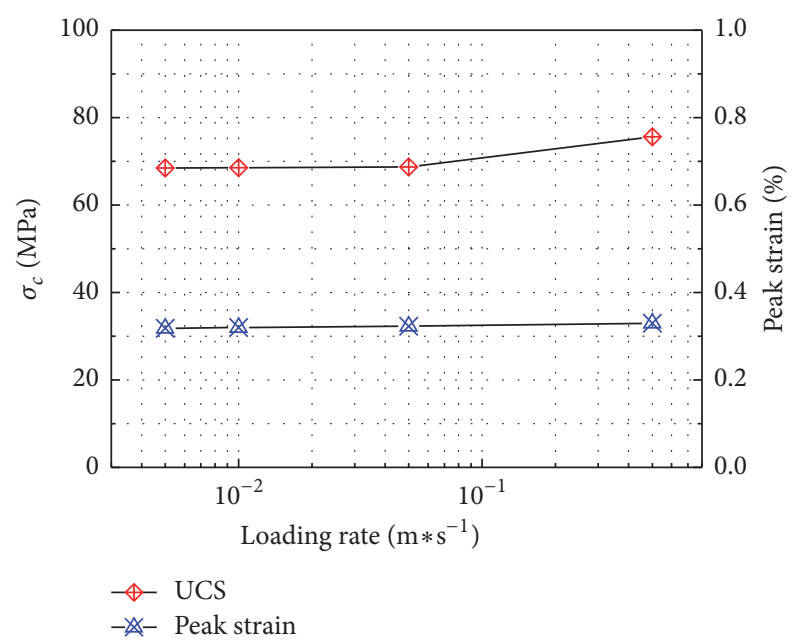

FIGURE 7: Relationships among uniaxial compression strength, peak strain, and loading rate.

and expansion, and softening and dilatation in three stages. The overall trend of stress and strain changes was not affected by the loading rate. The loading rate only affected the strain required to reach each stage. The postpeak stage indicates that, at a lower loading rate, the fractured rock sustained initial damage, and the crack had sufficient time to evolve and expand. The results demonstrate that the stress-strain curve of the specimen was step-like and decreasing. At a high loading rate, the stress-strain curve of the specimen was smooth and continuous.

Table 3 and Figure 7 indicate that the uniaxial compressive strength and the corresponding peak strain of the fractured rock mass increased nonlinearly with the loading rate. As the loading rate increased from 0.005 to $0.5 \mathrm{~m} / \mathrm{s}$, the uniaxial compressive strength increased by $10.36 \%$, and the corresponding peak strain increased by $3.77 \%$. However, the growth rate increased with the loading rate. The loading 


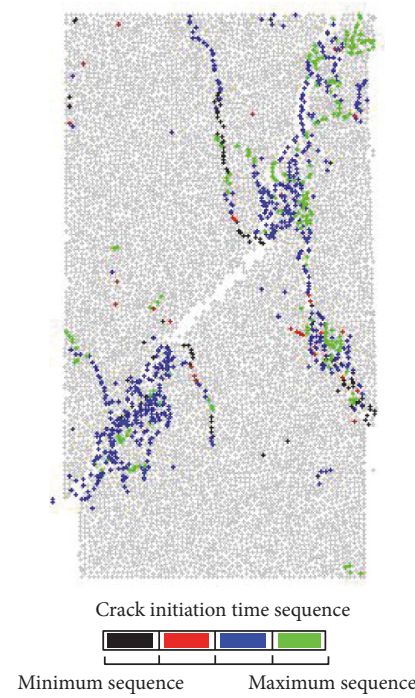

(a) $0.005 \mathrm{~m} / \mathrm{s}$

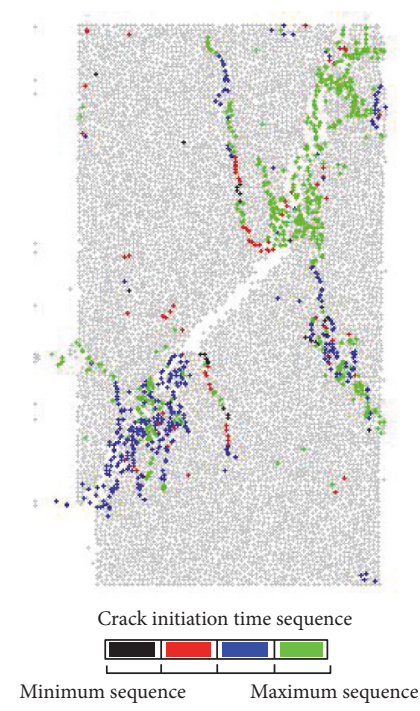

(b) $0.01 \mathrm{~m} / \mathrm{s}$

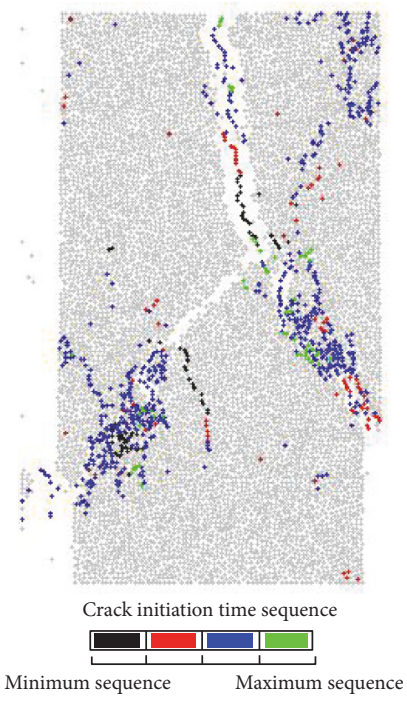

(c) $0.05 \mathrm{~m} / \mathrm{s}$

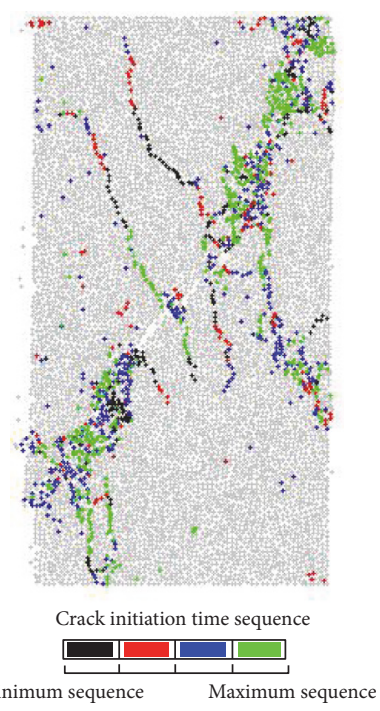

(d) $0.5 \mathrm{~m} / \mathrm{s}$

FIGURE 8: Damage evolution mechanism of fractured rock mass at different loading rates.

rate increased from $0.005 \mathrm{~m} / \mathrm{s}$ to $0.01 \mathrm{~m} / \mathrm{s}$, the uniaxial compressive strength increased by only $0.044 \%$, and the corresponding peak strain increased by $0.629 \%$. As the loading rate increased from $0.05 \mathrm{~m} / \mathrm{s}$ to $0.5 \mathrm{~m} / \mathrm{s}$, the uniaxial compressive strength increased by $10.04 \%$ and the corresponding peak strain increased by $2.167 \%$.

\subsection{The Effect of Loading Rate on the Crack Propagation.} To analyze the effect of the loading rate on the failure mode, in the numerical experiment, the FISH programming language was used to monitor internal cracks. The crack initiation time sequence was distinguished by four colors: black, red, blue, and green. The development and distribution of cracks are shown in Figure 8, where the crack initiation evolution sequence indicates the relative time sequence of crack initiation and propagation.

Figures 6 and 8 show that the uniaxial compression failure of the fractured rock mass underwent an elastic stage, a stable fracture propagation stage, an unstable fracture propagation stage, and a stable residual stage. In the elastic stage, under the effects of an external load, the specimen was tightly squeezed. When the external load reached the crack initiation strength of the fractured rock mass, microcracks began to appear; at this time, the damage was random. Thus, internally, the microcracks were randomly distributed (corresponding to the black crack distribution in Figure 8). With increased loading, the internal damage of the fractured rock increased, and a nucleus was formed; at this time, the sample entered the stable fracture propagation stage. With a continuous increase in loading, the damage in the crack nucleus began to accumulate, and the direction of crack propagation was distinct. When the stress reached its peak value, previously formed microcracks expanded along the crack tip direction at a high rate and formed the dominant crack, leading to failure of the rock mass. The sample entered the unstable fracture propagation stage (corresponding to the blue and green cracks in (d)

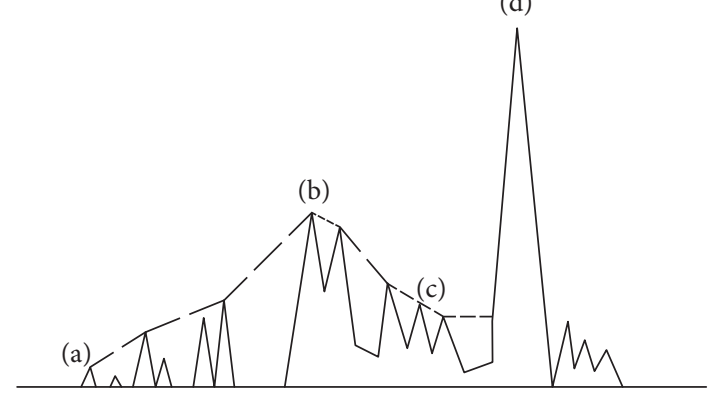
(a) Initial emission
(c) Shaped charge
(b) Critical instability
(d) Destruction

FIGURE 9: Curves of the general acoustic emission process.

Figure 8). The dominant fracture zone in Figure 8 illustrates that the crack propagated at a higher rate in the unstable propagation stage, forming the main controlled fracture.

5.3. The Effect of Loading Rate on Acoustic Emission Characteristics. During rock fracture accompanied by acoustic emission, to a certain extent, the crack number reflects the degree of damage to the rock itself. In a bonded particle model, when the bonding strength between particles is less than that of the particles, the particle bonds will break, corresponding to microcracks in rock [29]. During crack propagation, strain energy is released rapidly as an elastic wave, producing an infrasonic, sonic, or ultrasonic wave; this effect is the acoustic emission (AE) phenomenon, as shown in Figure 9. In Figure 9, the horizontal axis represents time. Because the particles in the $\mathrm{PFC}^{2 \mathrm{D}}$ were all approximately the same size (on the same order of magnitude), each bond breakage released approximately the same amount of energy [30]. 


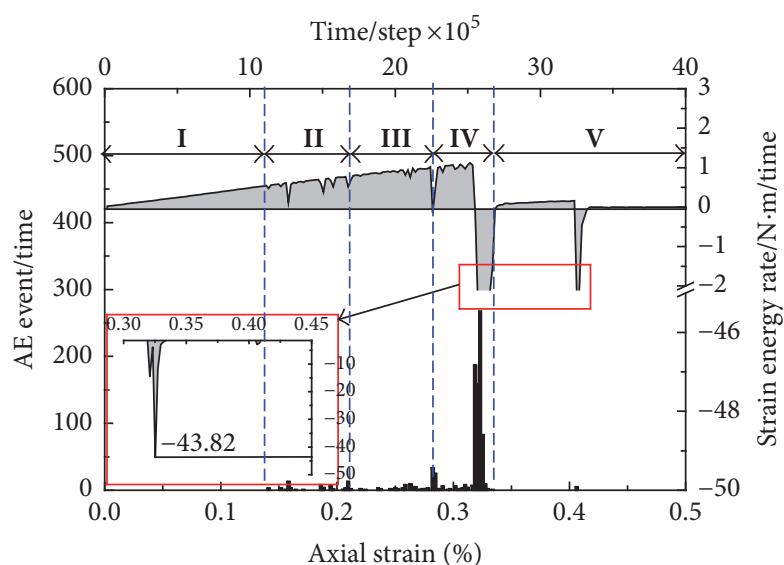

aE - Strain energy rate

(a) $0.005 \mathrm{~m} / \mathrm{s}$

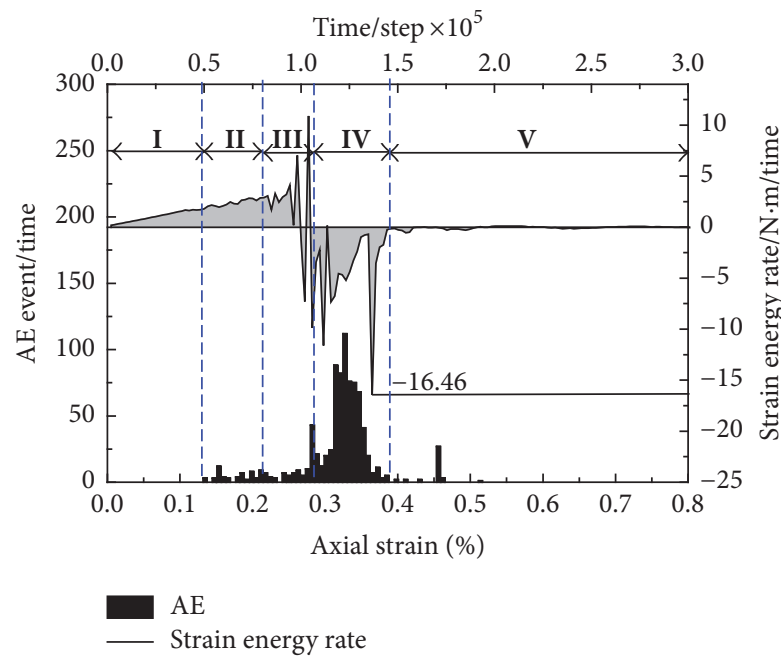

(c) $0.05 \mathrm{~m} / \mathrm{s}$

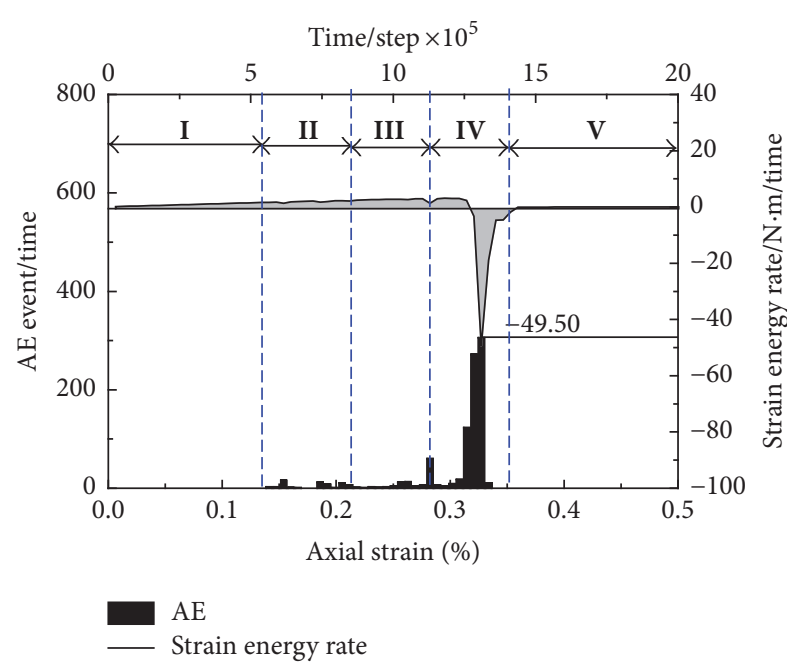

(b) $0.01 \mathrm{~m} / \mathrm{s}$

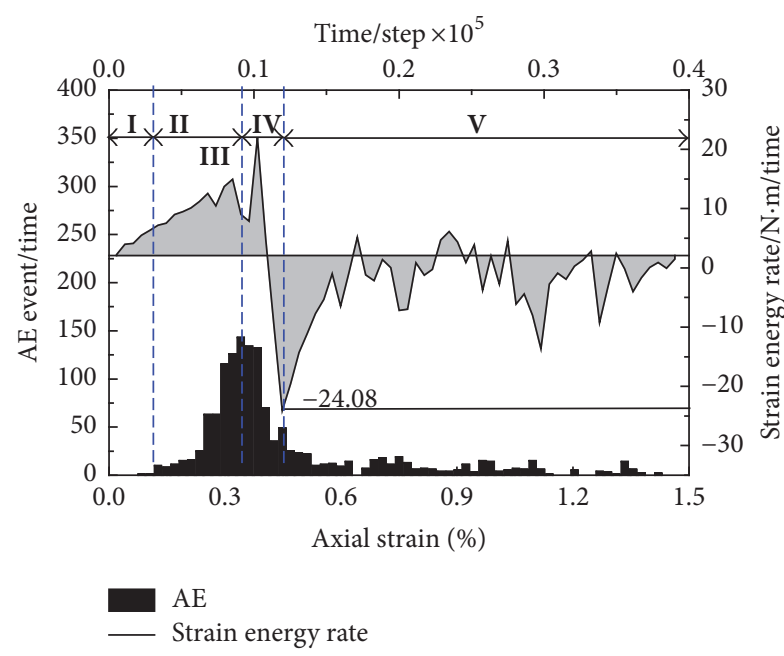

(d) $0.5 \mathrm{~m} / \mathrm{s}$

FIGURE 10: Curves of the axial stress-strain and acoustic emission frequency of the bonded particle model.

However, treating each bond breakage as an $\mathrm{AE}$ event in the $\mathrm{PFC}^{2 \mathrm{D}}$ is not valid for real microseismic and $\mathrm{AE}$ events. Hence, bond breakages occurring close in time and space are considered to be the same $\mathrm{AE}$ event in the present study. Figure 10 shows a curve of the fractured rock acoustic emission events and changes in strain energy as a function of changes in strain under different loading rates.

As shown in Figure 10, the specimen was subjected to external loading at the initial stage (stage I), the contact force between the particles could not overcome the bond strength, and no crack was produced. In this stage, the specimen was being squeezed tightly, and the strain energy could be absorbed and accumulated. The strain rate curve shows a linear increase, which indicates that the sample was in the elastic stage. With increasing load, the contact force of the particles macroscopically exceeded the bond strength, and the stress reached that required for macroscopic crack initiation. The production of microcracks resulted in the first set of $\mathrm{AE}$ events. In acoustic emission, the process line is defined by points denoted (a) in Figure 9. When entering the $\mathrm{AE}$ rising area (stage $\mathrm{II}$ ), the slope of the strain rate curve decreased. When it entered the nonlinear stage, the sample produced a weak set of acoustic emission events. It can also be observed that partial strain energy could be converted to elastic wave release, which led to a decrease in the strain energy absorption rate, and the sample entered the stable fracture propagation stage.

After entering stage III, the sample exceeded the critical instability point B. With a burst in acoustic emission, the strain energy was suddenly released. The strain energy curve indicates that the release was completed instantaneously. When the sample entered a relatively quiet period, the strain energy underwent a distinct absorption and accumulation process, mainly because of the sharp increase in the new free surface generated by crack propagation and the consumption of energy. In acoustic emission, the process line represents 
an energy absorption valley, which is located at cumulative point C. However, the strain energy was not stable at this stage, and a small amount of strain energy was released. The high-frequency, weak AE events could be observed based on the corresponding AE events as the sample entered the unstable fracture propagation stage. After a temporary equilibrium in crack growth, with increasing loading rate, the cracks began to propagate and coalesce. The strain energy was released rapidly, as evidenced by the sharp decline in the strain energy curve, and acoustic emission entered the explosive zone (stage IV). This stage features the peak acoustic emission event, when macroscopic failure occurs in a sample. Upon entering the outbreak stage (stage V), the microcrack expanded into a macroscopic crack, strain energy was released, the sample lost stability, and the intensity of acoustic emission was reduced. At this stage, the failure of the specimen was mainly due to the friction caused by sliding along the macroscopic crack. The results indicate that the sample had resumed the development of a stable fracture.

As shown in Figure 10, under uniaxial compression, the strain energy rate and acoustic emission events were all affected by the sample loading rate. With increasing loading rate, the $\mathrm{AE}$ events and strain energy rate initially increased, followed by decay and fluctuation. In the uniaxial compression test, as the loading rate was increased from 0.005 to $0.5 \mathrm{~m} / \mathrm{s}$, the maximum strain energy release rate at stage IV increased from 16.46 to 49.50 . The corresponding peak acoustic emission event increased from 112 to 306. Moreover, with increasing loading rate, acoustic emission events tended to be of the seismic cluster type (corresponding to stage IV in Figure 10). Figure 10 also demonstrates that the loading rate affected the duration of each stage; as the loading rate increased, the peak period of $\mathrm{AE}$ events occurred earlier.

\subsection{Failure Mechanism of Fractured Rock under Compression}

5.4.1. The Evolution of the Macroscopic Characteristics. To study the evolution characteristics of the internal components and macroscopic characteristics of fractured rock specimens during compression, the failure mechanism of the specimens was studied at a loading rate of $0.05 \mathrm{~m} / \mathrm{s}$ as an example. In Figure 11, six reference points are specified on the stressstrain curve to illustrate the evolution of stress and energy, the rotation of particles in the sample, the indirect contact force of the particles, and the evolution of microcracks during compression. Point A corresponds to the starting point of the compression test, $\mathrm{C}$ corresponds to the peak value of the deviatoric stress-axial strain curve, and $\mathrm{B}, \mathrm{D}, \mathrm{E}$, and $\mathrm{F}$ correspond to the points at which the axial strain reached $2.0 e-3,3.2 e-3,4.0 e-3$, and $1.0 e-2$, respectively.

As indicated in Figure 11, before the peak stress was reached, the specimen was in an elastic stage, and the stress and strain increased linearly. The number of cracks was low in the initial stage, and the growth rate was very small, mainly because the specimen compression was not aggressive in the initial stage; the displacement between particles was relatively small, but friction sliding and rotation between particles occurred easily, leading to the initiation of shear cracks. As the compression process continued, when the peak stress was

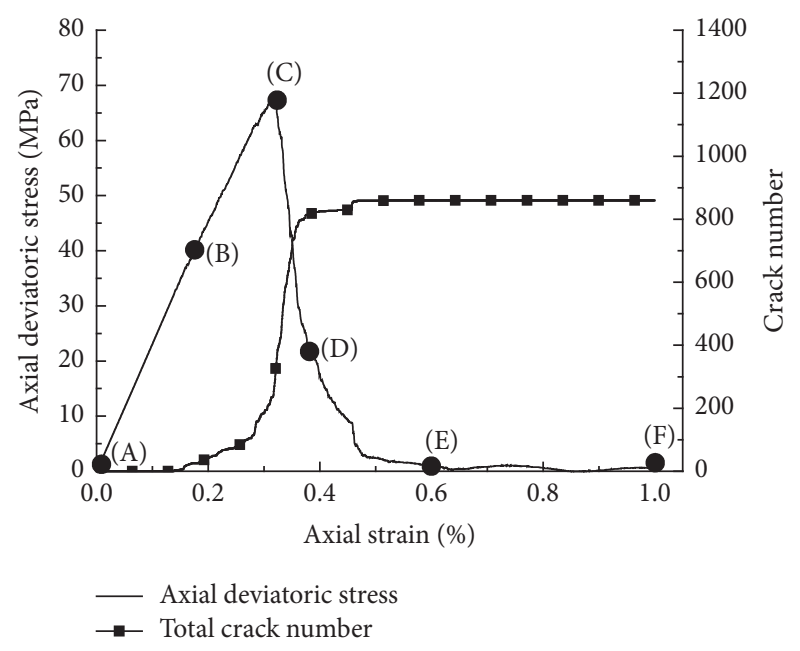

FIGURE 11: Evolution curves of axial deviatoric stress and crack number versus axial strain.

reached, the rate of crack growth increased suddenly; at this time, the specimen began to undergo macroscopic rupture. After the peak stress was attained, the number of cracks continued to increase and gradually stabilized. The stress was also very low because the specimen had been completely destroyed; thus, the bearing capacity was lost.

5.4.2. Evolution of the Particle Rotation Angle. The rotation of particles is herein defined as the cumulative angle of particle rotation during the compression test. Counterclockwise rotation is positive, and clockwise rotation is negative. In general, shear slip is often accompanied by the deflection of the particles, as shown in Figure 12. Particle rotation often results in shear dislocation between particles. When the shear force between the particles exceeds the tangential bonding strength between the particles, a shear crack is produced. Therefore, to some extent, the occurrence of shear cracks is caused by the rotation of particles; when the particle rotation angle is high, shear failure can occur in parallel bonding.

As shown in Figure 13, during compression, the rotation and evolution of the particles in the rock specimen showed partition characteristics. In the initial stage, the distribution of particle rotation angles was uniform. Because of the interaction of external loads and particles, the rotation of the particles gradually changed. Before reaching the peak strength, the particles undergoing clockwise rotation and counterclockwise rotation were distributed uniformly throughout the entire specimen. As the compression process continued, the partition characteristics of the particle rotation angle became increasingly distinct throughout the entire specimen. Finally, in the upper-right corner of the crack and the lower-left corner of the junction area, two large-rotation-angle areas of counterclockwise rotation formed. However, on both sides of the large-rotation-angle areas, the particle rotation angle gradually decreased, and the effect of the compressive load on these areas was not distinct. However, in the middle of the model on the right side, a large-rotation-angle area with clockwise rotation formed. By comparing with the crack 


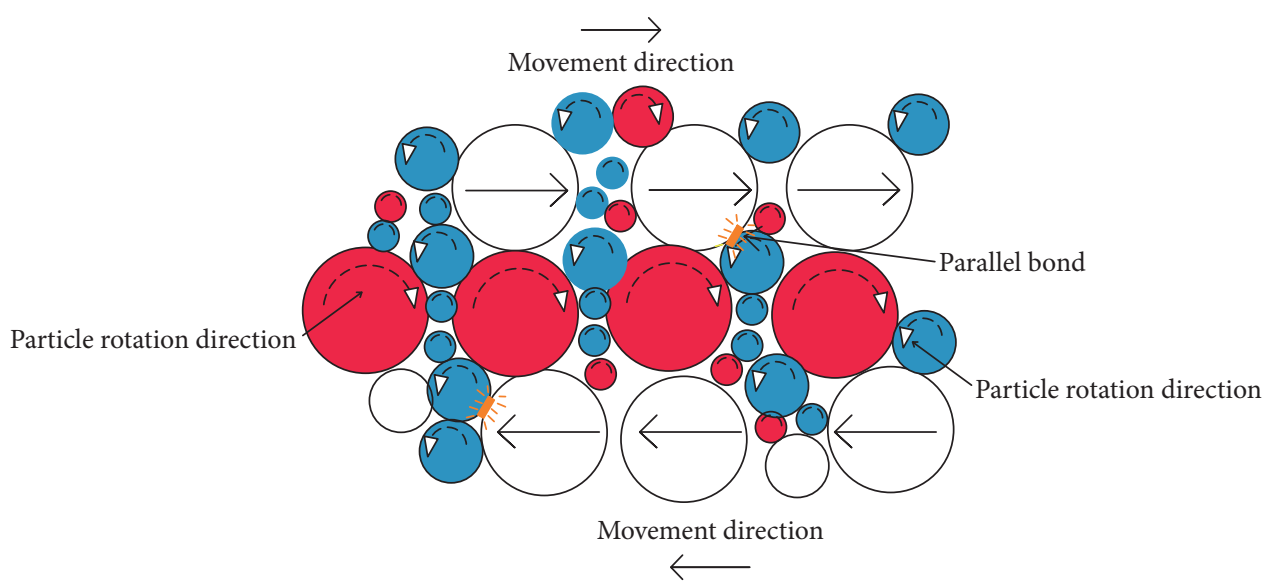

FIGURE 12: Illustration of particle rotation.

distribution, it was observed that the particles with large rotation angles were mainly distributed near the crack. It could be observed that the crack was related to the rotation of particles and that specimen compression also involved the redistribution particle rotation in the specimen. Moreover, with continuous crack generation, the results indicate that the failure mode changed from mesofracture to macroscopic failure.

In the compression test, the rotation angle of the particles was constantly evolving, and the proportion of each rotation angle group was constantly changing, as shown in Figure 14. In the initial stages of compression, the rotation angle of the particles was very small, between -0.005 and 0.005 radians. As the compression process continued, the proportion of particles with rotation angles between -0.005 and 0.005 decreased gradually, whereas the proportion of particles with rotation angles between -0.01 and -0.005 and between 0.005 and 0.01 increased. However, there was no change in the area where the absolute value of the other rotation was greater. When the peak stress at point $C$ was reached, there was a rapid increase in the proportion of particles with angles in the range of -0.01 to -0.005 , and the proportion of particles with angles in the range of 0.005 to 0.01 still grew steadily. These results indicate that clockwise rotation of particles was dominant. The number of particles with rotation angles between -7 and -0.01 and between 0.01 and 7 increased, but there were more particles with rotation angles ranging from 0.01 to 7 than particles with rotation angles ranging from -7 to -0.01 . After the failure of the specimen, the number of particles with a large rotation angle was reduced to a certain extent because these particles began to rearrange. This effect was mainly related to the location of specimen rupture and the fracture direction.

5.4.3. Evolution of Crack Propagation. Under compression by an external load, the internal particles of the specimen were extruded from each other, altering the relative displacement between the particles and their constant rotation, along with the continuous initiation and propagation of tensile cracks and shear cracks. Figure 15 shows the evolution of mesoscale cracks at each observation point. Shear cracks are shown in red and tensile cracks in black. Figure 15 indicates that when the compressive load was small, there were no cracks in the specimen, but with increasing compressive load, a shear crack began to form inside the specimen. This result occurred mainly because the relative displacement between the particles was small and the degree of particle extrusion was not severe. Owing to the rotation of particles, shear cracks formed. When the peak stress at point $\mathrm{C}$ was reached, many cracks appeared around the prefabricated crack. At this time, many tensile cracks began to dominate. The tensile cracks were mainly caused by the extrusion of the particles, which could lead to fracture. With the increase in the degree of extrusion between the particles, these cracks extended to the surrounding material. Both ends of the cracks propagated to the two corners of the specimen. Finally, it can be observed that the internal cracks of the specimen were penetrated. In the region where the cracks were distributed, a large void zone was produced. The specimen essentially lost its load-bearing capacity, and the specimen was destroyed. The mechanism underlying tensile crack formation is shown in Figure 16.

5.4.4. Evolution of Energy Conversion. It is well known that energy conversion is common in the physical world. The compression of rock cannot be separated from the evolution of energy. From an energy perspective, compression is the process of energy conversion in a specimen. The failure of a specimen is a type of unstable phenomenon driven by energy. Under a compressive load, energy dissipation in a model system is mainly caused by friction energy and viscous energy. The strain energy is composed of two parts: the first part is stored in the linear contact between particles, and the other part is stored in parallel bonding. The energy stored in parallel bonds is closely related to the generation and propagation of cracks. Thus, the conversion of energy can directly reflect the damage of fractured specimens. To some extent, this conversion can reveal the failure mechanism. Curves of energy conversion during compression are shown in Figure 17.

It can be observed that the evolution of the energy stored in linear contacts and that of energy stored in parallel 


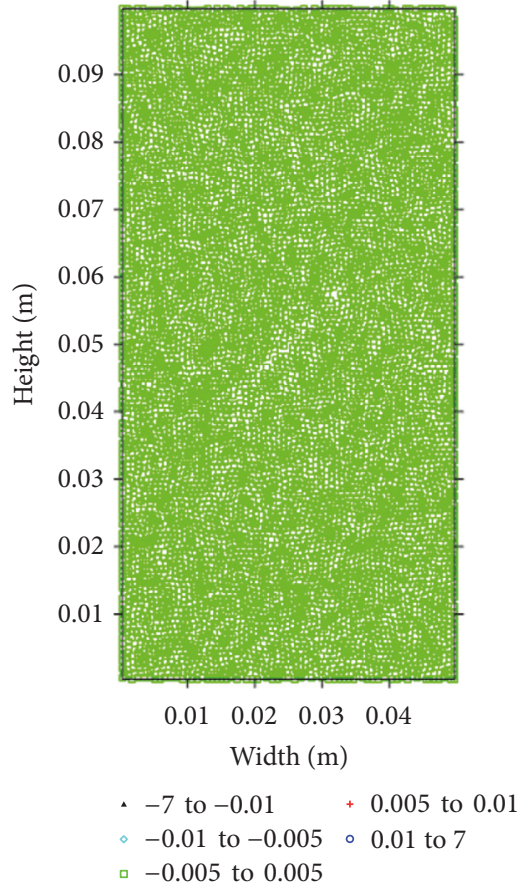

(a) Monitoring point $\mathrm{A}$

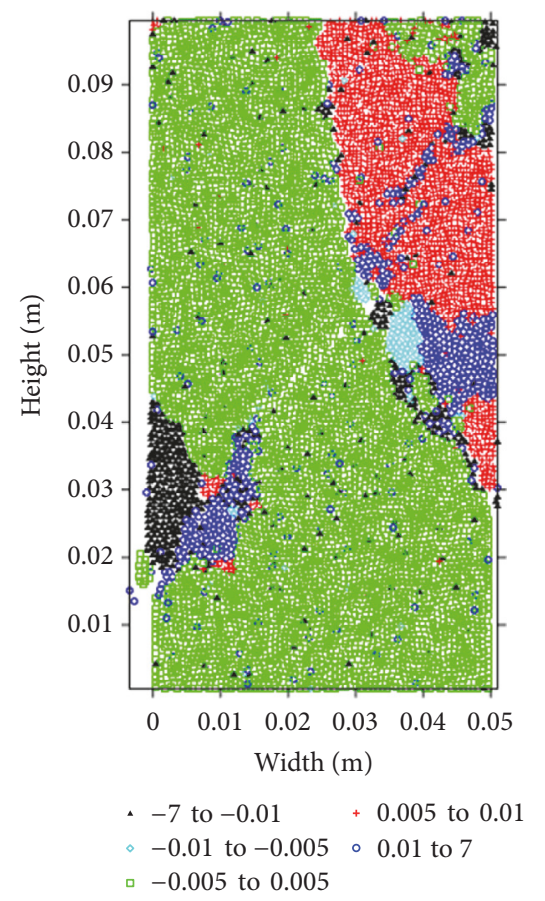

(d) Monitoring point $\mathrm{D}$

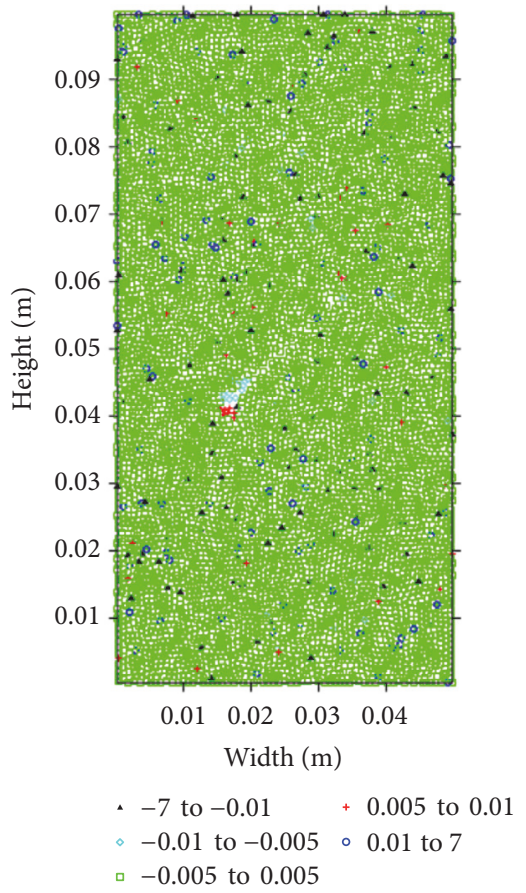

(b) Monitoring point $\mathrm{B}$

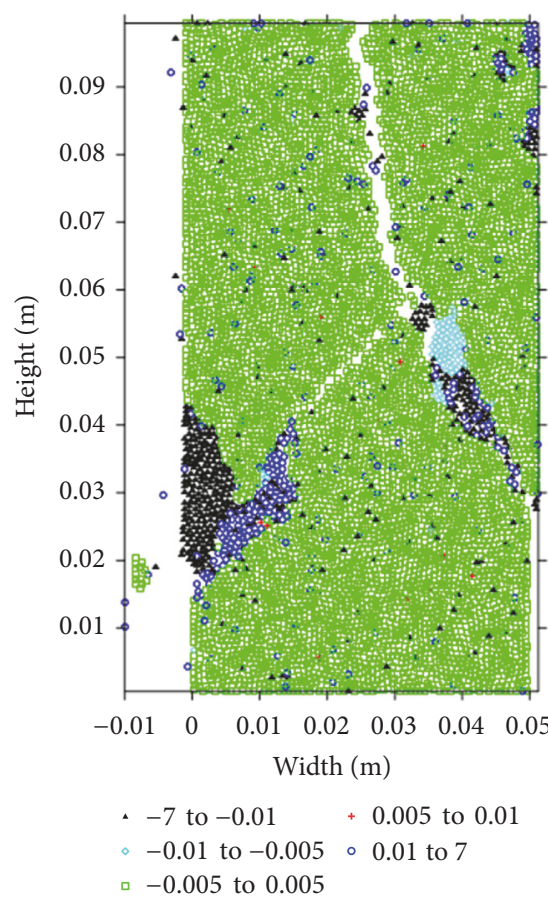

(e) Monitoring point $\mathrm{E}$

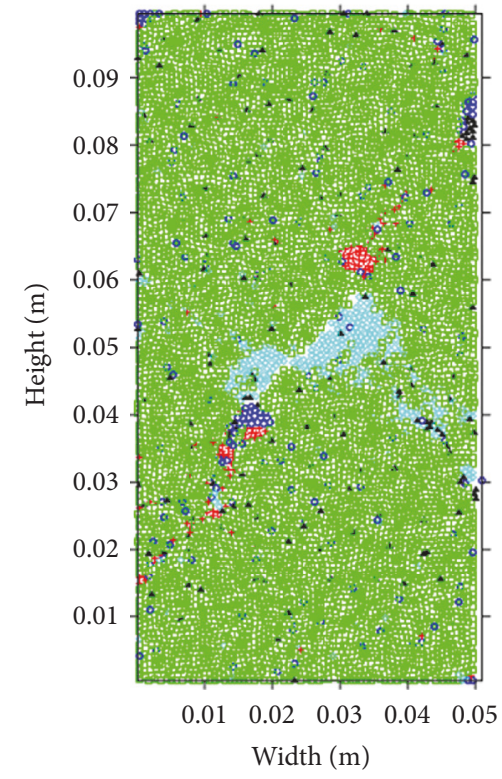

. -7 to $-0.01+0.005$ to 0.01

- -0.01 to $-0.005 \circ 0.01$ to 7

- -0.005 to 0.005

(c) Monitoring point $\mathrm{C}$

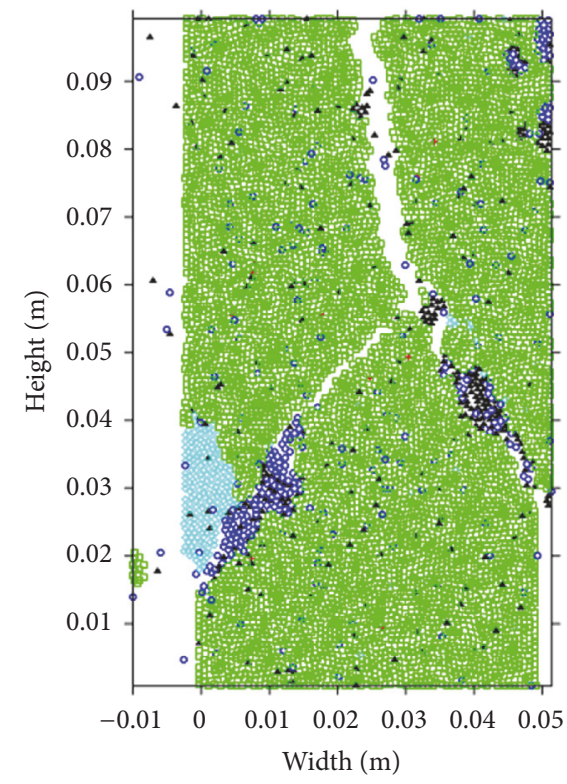

$\begin{array}{ll}- & -7 \text { to }-0.01 \quad+0.005 \text { to } 0.01 \\ - & 0.01 \text { to }-0.005 \text { ० } 0.01 \text { to } 7 \\ - & -0.005 \text { to } 0.005\end{array}$

(f) Monitoring point $\mathrm{F}$

FIGURE 13: Evolution of particle rotation angle in the sample.

bonding are essentially the same; before the peak stress is reached, the corresponding values gradually increase. This increase is due to the effect of external compressive loads; the work performed by the external load on the specimen is mostly stored in the specimen in the form of strain energy. The strain energy involves linear contact and parallel bonding. A small amount of energy is dissipated in the form of friction between particles and the viscous dissipation. Extrusion between particles must be accompanied by friction. Moreover, as the compression process continues, the dissipation of friction energy gradually increases because of the rupture of the specimen: the cracks between the 


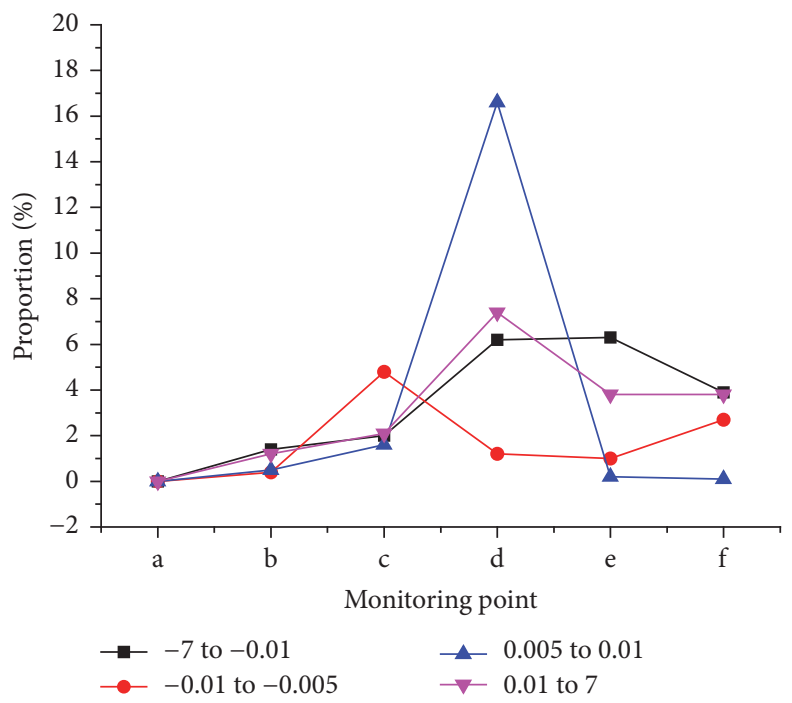

FIGURE 14: Change in the quantitative proportions of different rotation angles over time.

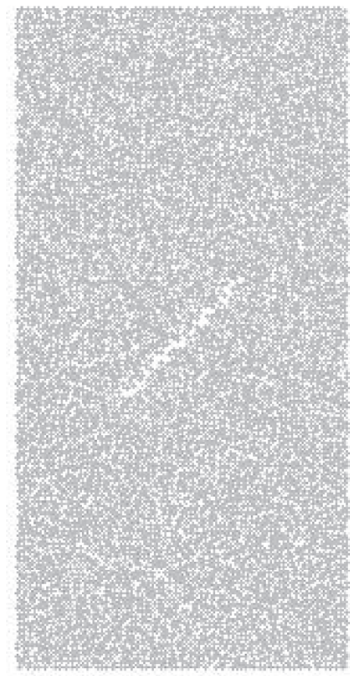

(a) Monitoring point $\mathrm{A}$

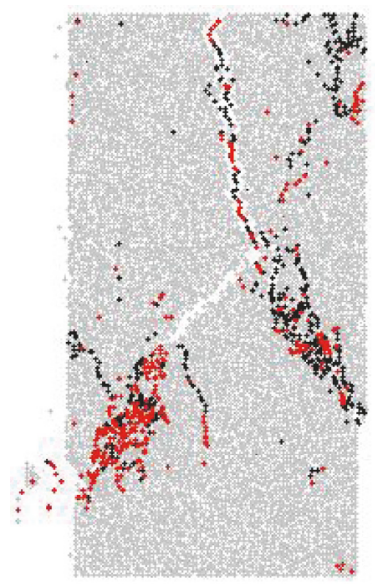

(d) Monitoring point $\mathrm{D}$

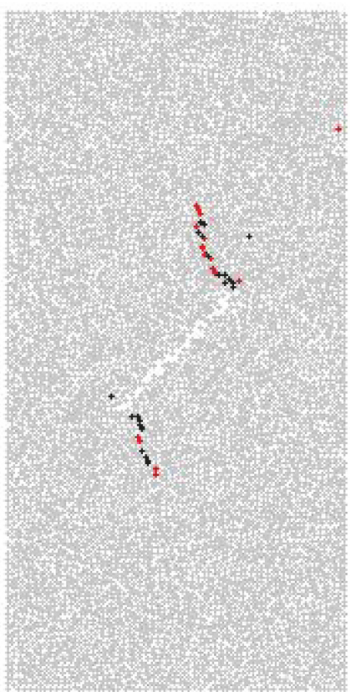

(b) Monitoring point $\mathrm{B}$

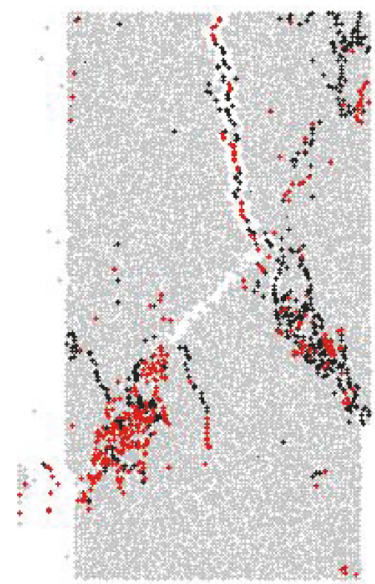

(e) Monitoring point $\mathrm{E}$

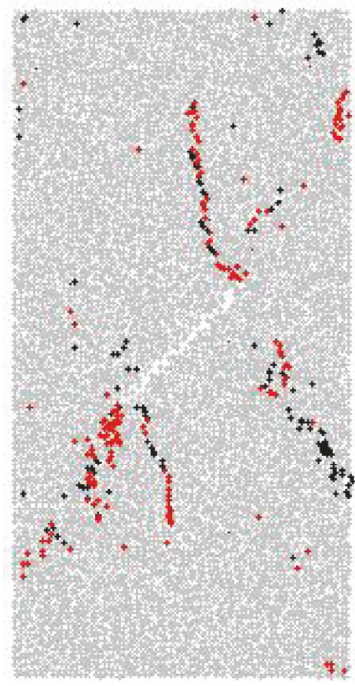

(c) Monitoring point $\mathrm{C}$

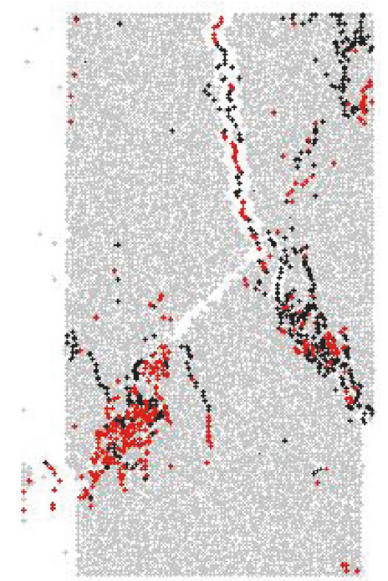

(f) Monitoring point $\mathrm{F}$

FIgURE 15: Evolution of microscopic cracks in a sample. 

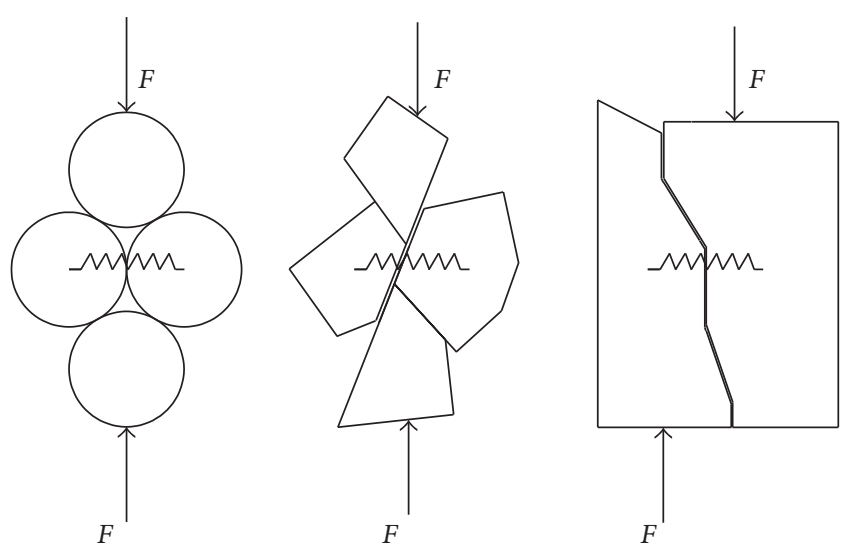

FIGURE 16: Illustration of the compression-induced tension crack mechanism.

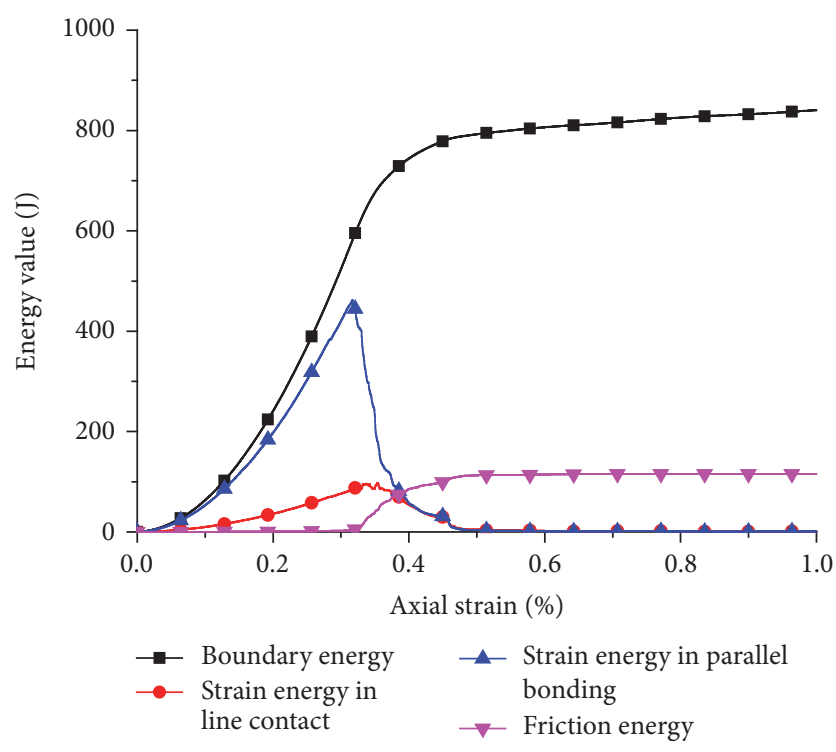

FIGURE 17: Curves of energy conversion during compression.

particles increase in size and number, and the movement of particles is strengthened, which results in increased frictional energy dissipation between particles. When the load-bearing capacity of the specimen depends on the friction force between the particles, the consumption of frictional energy is essentially constant.

\section{Conclusions}

In this study, a numerical simulation of a uniaxial compression test of fractured rock specimens was performed using discrete-element software $\left(\mathrm{PFC}^{2 \mathrm{D}}\right)$. The effects of different loading rates on the macroscopic strength and physical qualities of the specimens were studied from the perspective of rock particles. The acoustic emission characteristics and failure mechanism of the fractured rock specimens were revealed, and the following conclusions can be drawn.

(1) During compression, fractured rock experiences initial compaction, hardening and expansion, and softening and dilatation in three stages. The overall trend of stress and strain changes is not affected by the loading rate. The loading rate only affects the strain required to reach each stage. It can be observed from the postpeak stage that, at a low loading rate, the fractured rock sustains initial damage, and cracks have sufficient time to evolve and expand; these results demonstrate that the stress-strain curve of a specimen is step-like and decreasing. At a high loading rate, the stressstrain curve of the specimen is smooth and continuous.

(2) During loading, the uniaxial compressive strength and the corresponding peak strain of a fractured rock mass increase nonlinearly with the loading rate. However, with the increase in the loading rate, the uniaxial compressive strength and the corresponding peak strain growth rate will increase.

(3) The strain energy rate and acoustic emission events are affected by the loading rate of fractured rock. With an increase in the loading rate, AE events and the strain energy rate initially increase and then decrease, showing a fluctuating trend. Simultaneously, the loading rate affects the duration of each stage. With an increase in the loading rate, less time is required for the sample to enter the period of peak AE events.

(4) The macroscopic fracture process of rock occurs under the effects of an external load and via the interactions between internal particles; the fracture process of a rock specimen ranges from static to dynamic, from local to global, and from microscopic to macroscopic; and the process of energy dissipation is essential. Under an external load, the particles within a specimen are constantly squeezed, rotated, and displaced. This process is accompanied by energy dissipation via the production of internal tensile and shear cracks; their propagation and coalescence result in the formation of a macroscopic rupture zone.

\section{Conflicts of Interest}

The authors declare that there are no conflicts of interest regarding the publication of this paper.

\section{Acknowledgments}

This study was supported by the National Natural Science Foundation of China (nos. 51479108, 51379117, and 51509261), the China Postdoctoral Science Foundation (2015M580599), and the Taishan Scholar Talent Team Support Plan for Advantaged \& Unique Discipline Areas.

\section{References}

[1] W. F. Brace and E. G. Bombolakis, "A note on brittle crack growth in compression," Journal of Geophysical Research: Atmospheres, vol. 68, no. 12, pp. 3709-3713, 1963.

[2] M. Adams and G. Sines, "Crack extension from flaws in a brittle material subjected to compression," Tectonophysics, vol. 49, no. 1-2, pp. 97-118, 1978

[3] T. N. Dey and C.-Y. Wang, "Some mechanisms of microcrack growth and interaction in compressive rock failure," International Journal of Rock Mechanics and Mining Sciences, vol. 18, no. 3, pp. 199-209, 1981. 
[4] M. F. Ashby and S. D. Hallam, "The failure of brittle solids containing small cracks under compressive stress states," Acta Metallurgica et Materialia, vol. 34, no. 3, pp. 497-510, 1986.

[5] A. V. Dyskin and L. N. Germanovich, "A model of crack growth in microcracked rock," International Journal of Rock Mechanics and Mining Sciences, vol. 30, no. 7, pp. 813-820, 1993.

[6] R. H. C. Wong and K. T. Chau, "The coalescence of frictional cracks and the shear zone formation in brittle solids under compressive stresses," International Journal of Rock Mechanics and Mining Sciences \& Geomechanics Abstracts, vol. 34, no. 3-4, p. 366, 1997.

[7] B. Vásárhelyi and A. Bobet, "Modeling of crack initiation, propagation and coalescence in uniaxial compression," Rock Mechanics and Rock Engineering, vol. 33, no. 2, pp. 119-139, 2000.

[8] R. H. C. Wong, K. T. Chau, C. A. Tang, and P. Lin, "Analysis of crack coalescence in rock-like materials containing three flaws-part I: experimental approach," International Journal of Rock Mechanics and Mining Sciences, vol. 38, no. 7, pp. 909-924, 2001.

[9] E. Sahouryeh, A. V. Dyskin, and L. N. Germanovich, "Crack growth under biaxial compression," Engineering Fracture Mechanics, vol. 69, no. 18, pp. 2187-2198, 2002.

[10] H. Lee and S. Jeon, "An experimental and numerical study of fracture coalescence in pre-cracked specimens under uniaxial compression," International Journal of Solids and Structures, vol. 48, no. 6, pp. 979-999, 2011.

[11] Y. S. Wang, W. S. Sloan, and C. D. Sheng, "Numerical study of failure behaviour of pre-cracked rock specimens under conventional triaxial compression," International Journal of Solids and Structures, vol. 51, no. 5, pp. 1132-1148, 2014.

[12] J.-X. Ren and X.-T. Hui, "Primary study on meso-damage propagation mechanism of cracked-sandstone using computerized tomography under uniaxial compression," Rock and Soil Mechanics, vol. 26, pp. 48-52, 2005.

[13] S. Li, T. Li, G. Wang et al., "CT real-time scanning tests on rock specimens with artificial initial crack under uniaxial conditions," Chinese Journal of Rock Mechanics and Engineering, vol. 26, no. 3, pp. 484-429, 2007.

[14] S. Yang, X. Liu, and Y. Li, "Experimental analysis of mechanical behavior of sandstone containing hole and fissure under uniaxial compression," Chinese Journal of Rock Mechanics and Engineering, vol. 31, no. 2, pp. 3539-3546, 2012.

[15] A. A. Griffith, "The phenomena of rupture and flow in solids," Philosophical Transactions of the Royal Society A: Mathematical, Physical \& Engineering Sciences, vol. 221, pp. 163-198, 1920.

[16] N. B. Whittaker, N. R. Singh, and G. Sun, Rock Fracture Mechanics Principles, Design and Applications, Elsevier, 1992.

[17] P. A. Cundall, "Computer Model for Simulating Progressive, Large-Scale Movements in Block Rock Systems," Symposium of International Society of Rock Mechanics, vol. 1, no. ii-b, pp. 11-18, 1971.

[18] P. A. Cundall and O. D. L. Strack, "The distinct numerical model for granular assemblies,” Géotechnique, vol. 29, no. 1, pp. 47-65, 1979.

[19] D. O. Potyondy and P. A. Cundall, "A bonded-particle model for rock," International Journal of Rock Mechanics and Mining Sciences, vol. 41, no. 8, pp. 1329-1364, 2004.

[20] N. Cho, C. D. Martin, and D. C. Sego, "A clumped particle model for rock," International Journal of Rock Mechanics and Mining Sciences, vol. 44, no. 7, pp. 997-1010, 2007.
[21] J. Yoon, "Application of experimental design and optimization to PFC model calibration in uniaxial compression simulation," International Journal of Rock Mechanics and Mining Sciences, vol. 44, no. 6, pp. 871-889, 2007.

[22] X.-P. Zhang and L. N. Y. Wong, "Cracking processes in rock-like material containing a single flaw under uniaxial compression: a numerical study based on parallel bonded-particle model approach," Rock Mechanics and Rock Engineering, vol. 45, no. 5, pp. 711-737, 2012.

[23] S. Ming-rong and C. Jian-feng, Rock mechanics, 49-50, Tongji University Press, Shanghai, 2006.

[24] W.-Z. Zhong, K.-J. He, Z.-Y. Zhou, W. Xia, and Y.-Y. Li, "Calibration of damping coefficient in discrete element method simulation," Acta Physica Sinica, vol. 58, no. 8, pp. 5155-5161, 2009.

[25] G.-Q. Zhou, J. Zhou, Y. Lu, and T. Li, "Selection of damping parameters used in a particle flow code $\left(\mathrm{PFC}^{2 D}\right)$," Journal of China University of Mining and Technology, vol. 40, no. 5, pp. 667-672, 2011.

[26] A. J. Feustel, "Seismic attenuation in underground mines: A comparative evaluation of methods and results," Tectonophysics, vol. 289, no. 1-3, pp. 31-49, 1998.

[27] J. Hazzard and B. Damjanac, "Further investigations of microseismicity in bonded particle models," in Proceedings of the $3 \mathrm{rd}$ international FLAC/DEM symposium, pp. 22-24.

[28] A. McGarr, "Some comparisons between mining-induced and laboratory earthquakes," Pure and Applied Geophysics, vol. 142, no. 3-4, pp. 467-489, 1994.

[29] J. F. Hazzard, R. P. Young, and S. C. Maxwell, "Micromechanical modeling of cracking and failure in brittle rocks," Journal of Geophysical Research: Solid Earth, vol. 105, no. 7, pp. 1668316697, 2000.

[30] J. F. Hazzard and R. P. Young, "Simulating acoustic emissions in bonded-particle models of rock," International Journal of Rock Mechanics and Mining Sciences, vol. 37, no. 5, pp. 867-872, 2000. 


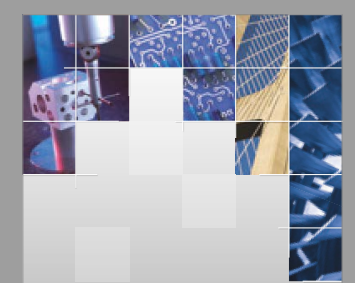

\section{Enfincering}
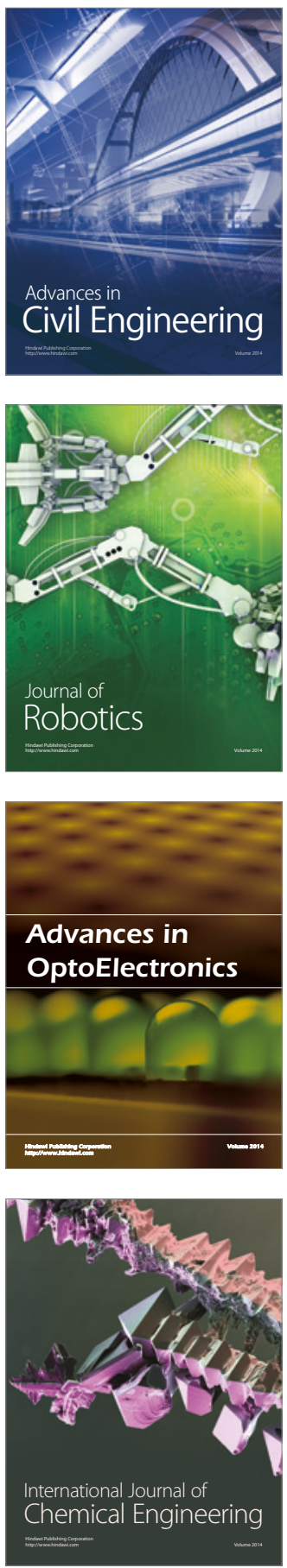

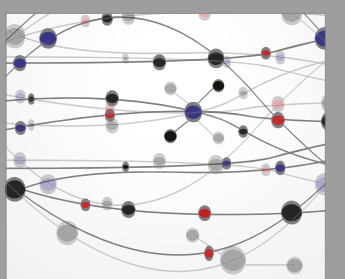

The Scientific World Journal

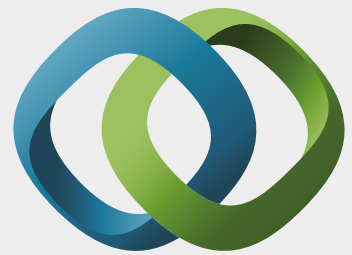

\section{Hindawi}

Submit your manuscripts at

https://www.hindawi.com
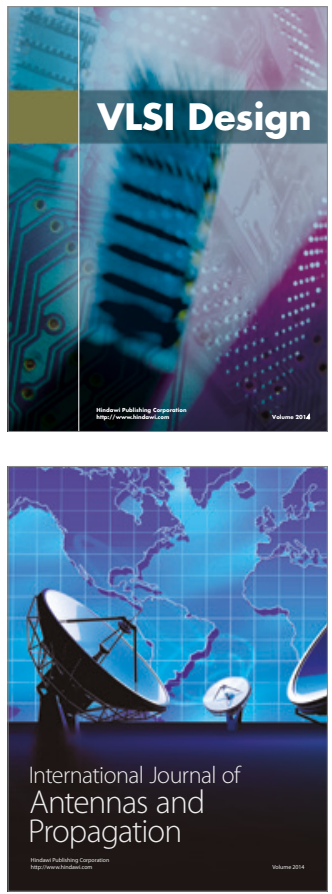

\section{Rotating}

Machinery
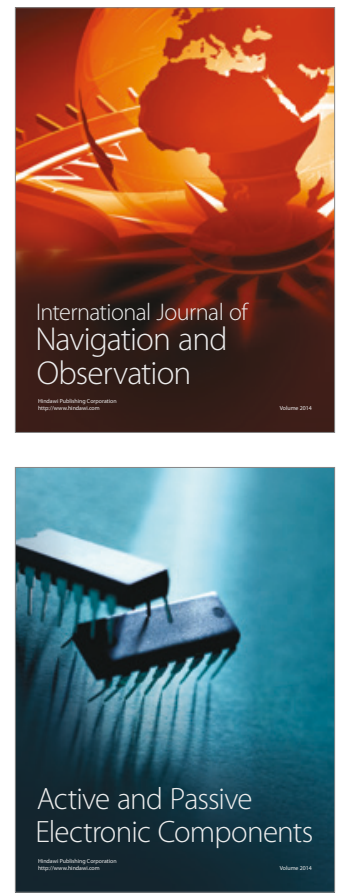
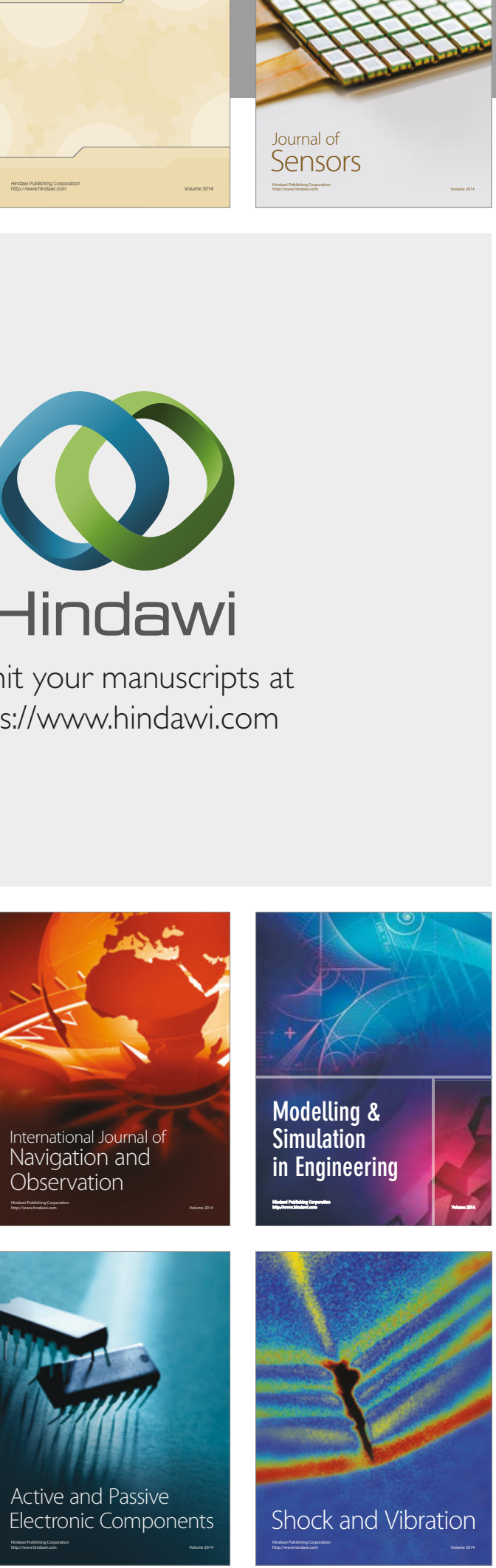
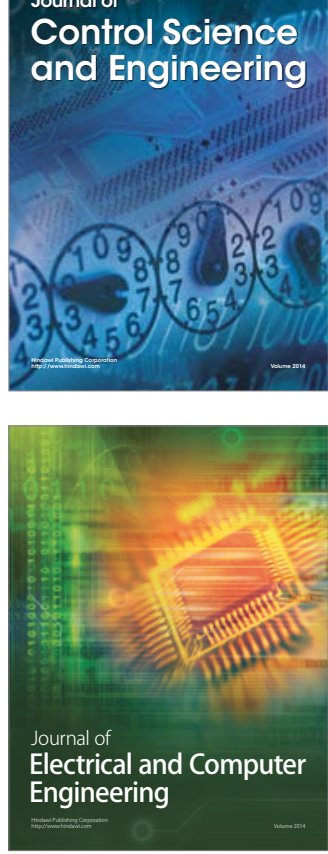

Distributed

Journal of

Control Science

and Engineering
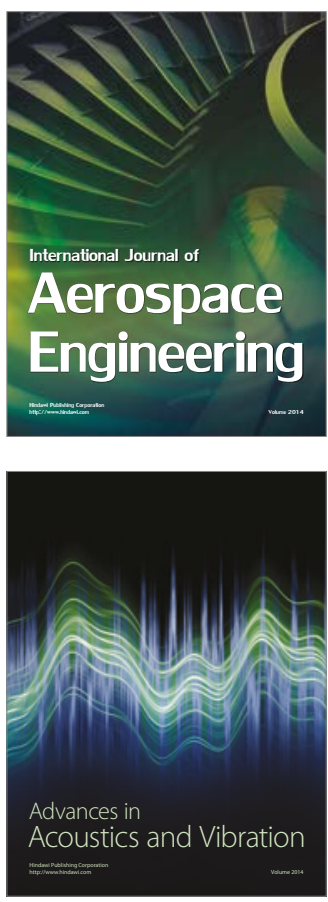

Sensor Networks 